\title{
Tsunami Hazard for the Crimean Coast of the Black Sea and the Kerch Strait at the Catastrophic Tsunamigenic Earthquakes, the Locations of which are Close to that of the Historical Yalta Earthquake on September 12, 1927
}

\author{
E. A. Baranova ${ }^{1}$, R. Kh. Mazova ${ }^{1,2, *}$ \\ ${ }^{1}$ Nizhny Novgorod State Technical University n. a. R.E. Alekseev, Nizhny Novgorod, \\ Russian Federation \\ ${ }^{2}$ Moscow Institute of Physics and Technology (National Research University), Dolgoprudny, \\ Russian Federation \\ * raissamazova@yandex.ru
}

Purpose. The main purpose of the work is to assess a possible tsunami hazard for the region of location of the Crimean Bridge constructed across the Kerch Strait, since up to present, numerical simulations of the tsunamigenic earthquakes in the Black Sea have never taken the Kerch Strait region (except for the water area at the strait entrance) into consideration as a possible object for a tsunami hazard.

Methods and Results. To assess a tsunami hazard for the Kerch Strait and, particularly, for the region of location of the constructed Crimean Bridge, the present paper considers the historical catastrophic tsunamigenic earthquake in the southeastern part of the Crimea Peninsula on September 12, 1927 as well as possible strong earthquakes, the source locations and magnitudes of which can be close to those of the above-mentioned one. The available data on localization and intensity of the earthquake on September 12, 1927 allowed to model the source of such an earthquake. Besides, within the framework of the nonlinear shallow water equations, simulated were the tsunami generation and the tsunami waves' propagation from the single- and two-block seismic sources in the Black Sea along the Crimea Peninsula, at the Kerch Strait entrance and in its water area. The seismic sources of close localization were similarly simulated for two possible tsunamigenic earthquakes in the southeastern part of the Crimea Peninsula.

Conclusions. For all the considered scenarios, generation and propagation of the tsunami waves over the water area regions under study were numerically simulated, the histograms of distribution of the wave run-up maximum heights along the Crimea Peninsula and the Kerch Strait coasts were constructed. It is shown that for all the scenarios, in the region of the Crimean Bridge western pillars the tsunami wave heights do not exceed $0.3-0.5 \mathrm{~m}$, whereas in the region of its eastern pillars, possible wave heights are within the range $0.6-1.95 \mathrm{~m}$. The results represented in the paper are compared with the available data on the wave heights in a number of settlements of the Crimea Peninsula coast and at the Kerch Strait entrance, obtained by the other authors.

Keywords: earthquake source, numerical simulation, generation of tsunami waves, histogram of tsunami wave maximum heights, Crimea, Kerch Strait

For citation: Baranova, E.A. and Mazova, R.Kh., 2020. Tsunami Hazard for the Crimean Coast of the Black Sea and the Kerch Strait at the Catastrophic Tsunamigenic Earthquakes, the Locations of which are Close to that of the Historical Yalta Earthquake on September 12, 1927. Physical Oceanography, [e-journal] 27(2), pp. 110-125. doi:10.22449/1573-160X-2020-2-110-125

DOI: $10.22449 / 1573-160 X-2020-2-110-125$

(C) E.A. Baranova, R.Kh. Mazova, 2020

(C) Physical Oceanography, 2020

\section{Introduction}

On September 12, 1927, at night a catastrophic tsunamigenic earthquake with a magnitude ranging within the interval $M=7-8$ occurred on the Crimean Peninsula coast (see, for example, [1-6]). Its center was under the seabed, south of Yalta and 
was extended along the coast. The approximate coordinates of the epicenter were $44.4^{\circ} \mathrm{N}, 34.5^{\circ} \mathrm{E}$. This earthquake became a real disaster in Crimea: according to the research data, there were more than 60 people dead, over 700 - wounded and injured, accompanied with the tremendous destruction. An earthquake was manifested outside the peninsula. In Yalta and its vicinity, the magnitude of the earthquake reached 8, in Sevastopol, Simferopol and Alushta 7, in Feodosiya and Yevpatoriya $\sim 6$, in Kerch the magnitude was close to 5 [1-4].

The recollections of eyewitnesses of this event are presented in the Yalta archive: “... Unusual in absolutely calm weather excitement in the form of a small swell looking like a "boiling sea" made even the bravest (fishermen) return to the coast. At midnight, dogs howled across the coast. After 15 minutes, a loud rumble interrupted the howl and the earth shook. Glass burst in houses, parget fell, floors and ceilings cracked, iron sheets rattled on roofs and stone walls of houses fell. People screamed from open windows. The first shock, lasting no more than 10 seconds, was followed by the second one. People began to run out of their houses, in which walls were cracked, furniture fell, balconies and cornices collapsed, and immediately the lights went out in the entire town. The ongoing disasters, collapsing buildings, groans of the wounded, caused extreme panic ... "[3]. Landslides and mudflows occurred in the mountains. Their traces, as on Mount Demerdzhi and in the mountains near Sudak, are still found after 90 years. Until noon on September 12, 1927, 27 strong shocks occurred. In just a few days, more than 200 shocks were recorded. The most powerful shocks led to the destruction of the coastal strip of land from Alushta to Sevastopol. Almost all stone buildings were damaged in the Yalta region. The total damage to the southern coast of Crimea was estimated at about 50 million rubles [4]. Aftershocks of this earthquake that occurred in Crimea at night of September 11 to 12 left $48 \%$ of residents of south-coastal villages homeless ${ }^{1}$.

The seismic and tsunami hazard assessments of the Black Sea, both Russian and other coasts of this water area, have been the subject of many works (see, for example, [7-18]). However, despite the proposed analytical methods and models for simulation of the generation and propagation of tsunami waves, the question of the possible danger of the Black Sea tsunami remains relevant, in particular, in connection with the operation of the recently built Crimean Bridge across the Kerch Strait.

The present paper considers the tsunami hazard of the Kerch Strait region and the constructed Crimean Bridge with the possible repetition of a catastrophic earthquake similar to the one that occurred on September 12, 1927 in the southeast of the Crimean Peninsula with a localization of the source close to a historical earthquake. Complex geological conditions such as seismicity, tectonic fault and weak soils [19-21] require the most detailed analysis of all possible events that affect the seismic and tsunami stability of the unique structure constructed. In this regard, the work examines in detail the possibility of repeating the historical catastrophic event of September 12, 1927 with numerical modeling of earthquake sources of various configurations while maintaining the localization of the source in the southeast of the Crimean Peninsula.

${ }^{1}$ Sidorenko, A.V., 1969. Geologiya SSSR. Tom VIII. Krym. Chast' I. Geologicheskoye Opisanie [Geology of the USSR. Volume VIII. Crimea. Part I. Geological description]. Moscow: Nedra. 576 p. (in Russian).

PHYSICAL OCEANOGRAPHY VOL. 27 ISS. 2 (2020) 


\section{Formulation of the problem}

The article analyzes three possible scenarios of tsunami propagation for selected source locations. According to Scenario 1, for modeling the tsunami source, an elliptical seismic source was selected, located, according to historical data, south of Yalta and extended along the coast with approximate coordinates of the epicenter of $44.4^{\circ} \mathrm{N}, 34.5^{\circ} \mathrm{E}$ (see, e.g., $[1,5,6]$ ) (shown in purple in Fig.1). An earthquake with a magnitude of $\mathrm{M}=7$ was considered. According to Scenario 2, with the localization of the source on the same fault, a hypothetical earthquake with a magnitude of $\mathrm{M}=7.5$ was considered, the source consisted of two semi-elliptical blocks, and the block separation line with the line of the Earth's crust fault (black line in Fig. 1).

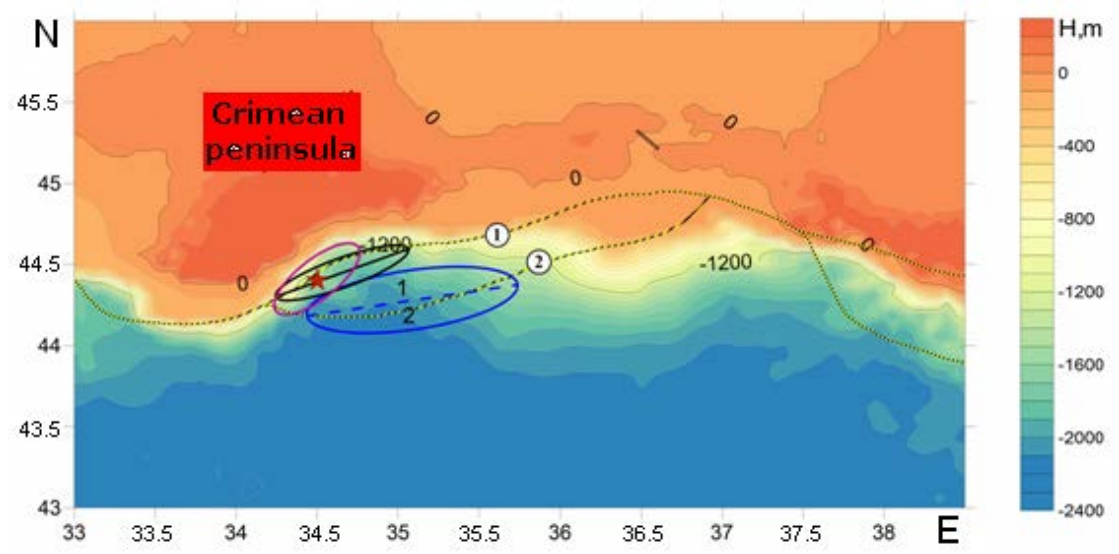

F i g. 1. The regions of the Crimean Peninsula and the Kerch Strait on the bathymetric map of the Black Sea. Black-yellow curves indicate the fault lines in the northeastern Black Sea, ellipses localization of the simulated earthquake source, red asterisk - localization of the historical earthquake (1927) epicenter

The hypothetical earthquake source with magnitude $\mathrm{M}=8$, located in the far zone of active Earth's crust faults near the Crimean Peninsula, was considered in Scenario 3. Similarly to Scenario 2, the earthquake source is an ellipse divided into two blocks by a line coinciding with the major axis of the ellipse. The localization of the source for Scenario 3 is shown by the blue line in Fig. 1.

For a detailed study of the wave characteristics when considering these scenarios in the region of the western and eastern supports of the Crimean Bridge and at some points along the coast of Crimea, virtual tide gauges were placed (Fig. 2). They recorded the water level variation near the bridge on a three-meter isobath.

Using Wells [22] and Iida $^{2}$ formulas, the source sizes and the estimated displacement of the Earth's crust in them at the magnitudes of earthquakes under consideration (see, e.g., $[13,15]$ ) were obtained. This data is given in Table 1 . For block sources (scenarios 2 and 3), the numbering of blocks is indicated by the numbers 1 and 2, respectively (Fig.1).

${ }^{2}$ Vol'tsinger, N.E., Klevannyj, K.A. and Pelinovskij, E.N., 1989. Dlinnovolnovaya Dinamika Pribrezhnoj Zony [Long-Wave Coastal Dynamics]. Leningrad: Gidrometeoizdat, 271 p. (in Russian). 


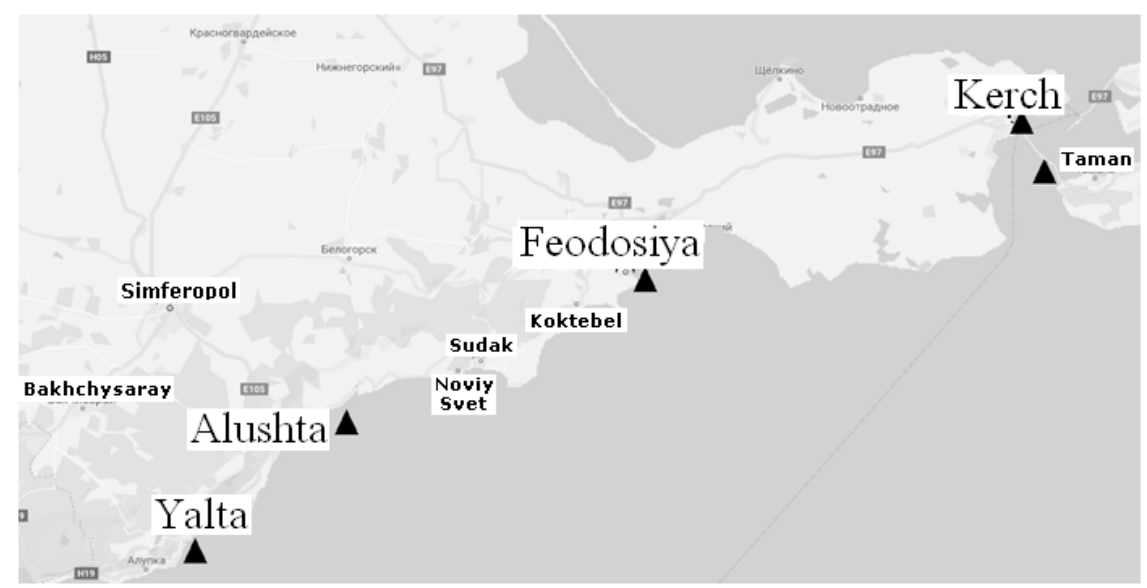

F i g. 2. Localization of the virtual tide gauges ( $\mathbf{\Delta})$ along the Crimean Peninsula and in the Kerch Strait

Table 1

Parameters of the simulated earthquake sources

\begin{tabular}{c|c|c|c|c|c|c|c}
\hline $\begin{array}{c}\text { / Scenario } \\
\text { number }\end{array}$ & Magnitude & $\begin{array}{c}\text { Length, km } \\
\text { (semi-axis) }\end{array}$ & $\begin{array}{c}\text { Width, km } \\
\text { (semi-axis) }\end{array}$ & Rise height, m & \multicolumn{2}{c}{ Rise time, s } \\
\hline 1 & 7.0 & 34 & 12 & \multicolumn{2}{|c}{1} & \multicolumn{2}{|c}{30} \\
\hline 2 & 7.5 & 48.5 & 18 & block 1 & block 2 & block 1 & block 2 \\
\cline { 5 - 8 } & \multirow{2}{*}{3} & & & -1.0 & 2.5 & 30 & 30 \\
\hline & 8.0 & 73.0 & 20 & block 1 & block 2 & block 1 & block 2 \\
\cline { 5 - 8 } & & & & -1.5 & 4.5 & 30 & 30 \\
\hline
\end{tabular}

Numerical simulation of a historical tsunamigenic earthquake in Crimea on September 12, 1927 with $M=7$ and a source located in the fault zone of the Earth's crust near the Crimean Peninsula (Scenario 1)

To describe the process of wave generation and propagation caused by the movements of key blocks in a seismic source, a nonlinear system of shallow water equations in a two-dimensional formulation was used (see, e.g., [13, 15]). In the numerical description of the tsunami wave generation and propagation over the water area, a scheme constructed by analogy with the Sielecki difference scheme [23] is applied. A computational grid is introduced with spatial intervals $\Delta x, \Delta y$ and time steps $\Delta t=1$ sec (see, e.g., [23]). In the computations presented in this work, the Black Sea bathymetry with the spatial step approximately $900 \mathrm{~m}$ is used. At the last seaward point at a depth of $3 \mathrm{~m}$, the condition of total reflection (vertical wall) was set, allowing to fix the maximum and minimum values of the wave displacement at this depth level.

To simulate the tsunami source of the historical Yalta earthquake, a seismic source with the parameters corresponding to the data of the September 12, 1927 earthquake, was considered. The location of the seismic source for this scenario is shown in Fig. 3a. The epicenter, according to historical data, was located on line 1 of the fault (shown by the purple line in Fig. 1). During the implementation of Scenario 1, an elliptical-shaped block rose to a height of $1 \mathrm{~m}$ in $30 \mathrm{~s}$ (Tab. 1). 

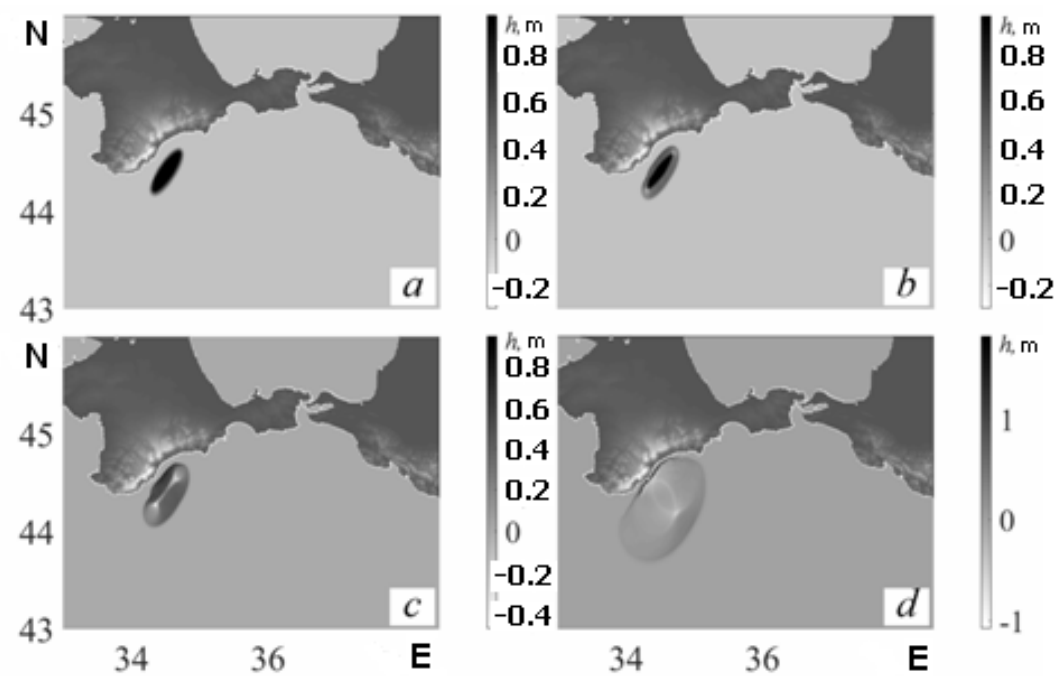

F i g. 3. Generation of tsunami source and position of the tsunami wave fronts in the Black Sea water area, Scenario $1(\mathrm{M}=7$ ) for 4 time moments: $a) t=30 \mathrm{~s} ; b) t=1 \mathrm{~min} ; c) t=2 \mathrm{~min}$; $) t=7 \mathrm{~min}$

It is clearly seen (Fig. 3) that there is an arc-like elevation wave coming to the coast, which reaches the coast of Crimea 7 minutes after the start of tsunami wave generation. The maximum wave height when approaching the coast (up to $0.8 \mathrm{~m}$ ) is observed in the region of Alushta (Fig. 3, $c$ ).

Fig. 4 shows a histogram of the distribution of maximum tsunami wave heights along the Crimean Peninsula in this simulation for the magnitude of the earthquake $M=7$. It can be clearly seen that the peak height for Scenario 1 was $2.7 \mathrm{~m}$ near Alushta. The highest wave heights are observed in the interval $34.2^{\circ}-34.6^{\circ} \mathrm{E}$ in the region of Yalta and Alushta, which, according to historical data, were badly damaged. Further along the coast from Koktebel to Kerch (located at the entrance to the water area of the Kerch Strait), the wave heights do not exceed $0.8 \mathrm{~m}$.

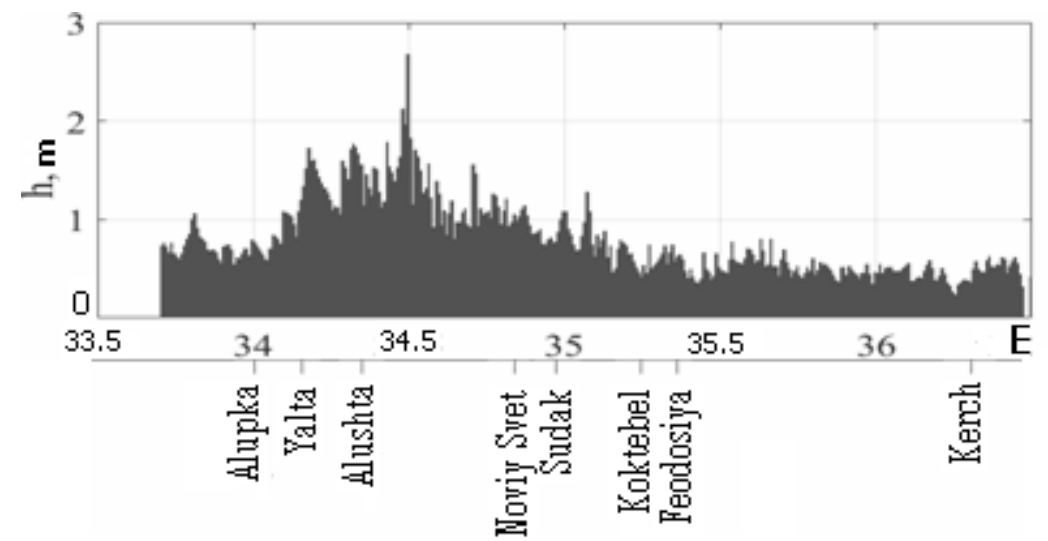

F i g. 4. $2 D$ histogram of distribution of the wave maximum heights on the 3-meter isobath nearby the Crimean coast, Scenario $1(\mathrm{M}=7)$ 
When approaching the Kerch Strait, the wave heights significantly decrease and do not exceed $0.4 \mathrm{~m}$ on average. At the beginning of wave propagation in the Kerch Strait, its leading front was arc-shaped. As the wave moves in the strait, its height decreases and the leading front approaches the eastern pillars of the Crimean Bridge with a height of about $30 \mathrm{~cm}$ (Fig. 5, d), to the western pillars with a height of about $20 \mathrm{~cm}$ (Fig. 5, c). 2 hours after the start of propagation, the wave passes the Crimean Bridge and continues to move towards the Sea of Azov.
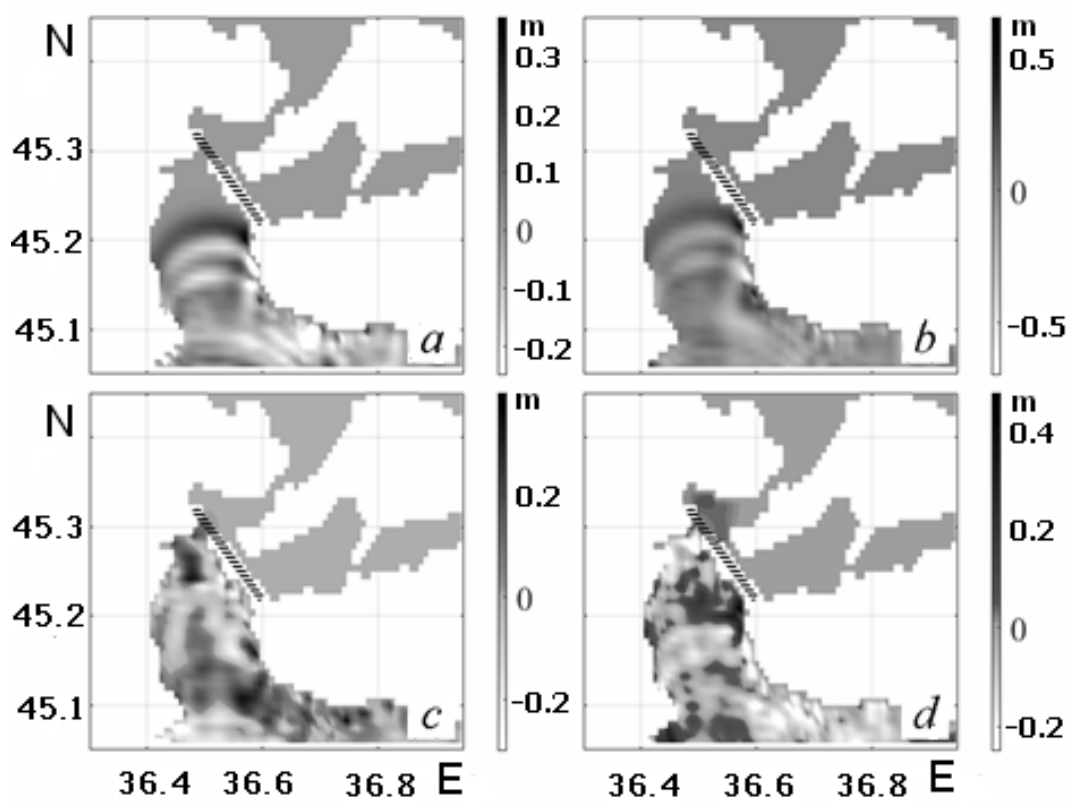

F i g. 5. Position of the tsunami wave fronts in the Kerch Strait water area, Scenario $1(M=7)$ : a) $t=1 \mathrm{~h} 35 \mathrm{~min}$; b) $t=1 \mathrm{~h} 40 \mathrm{~min}$; ) $t=2 \mathrm{hrs}$; $) t=2 \mathrm{hrs} 20 \mathrm{~min}$. Dark line denotes schematic location of the bridge

\section{Numerical simulation of a tsunami with a hypothetical source earthquake $(M=7.5)$, localized in the fault zone of the Earth's crust near the Crimean Peninsula (Scenario 2)}

In the implementation of Scenario 2, a model seismic elliptical source was used (black line in Fig. 1), divided into two parts along the major axis of the ellipse, which coincides with Line 1 of the Earth's crust fault. The block begins to move first (Fig. 1), oriented toward the coast. The movement takes 30 seconds (Table 1), during this time the block evenly lowered down by $1 \mathrm{~m}$. Simultaneously with this movement, the second block oriented to the sea also moved up to a height of $2.5 \mathrm{~m}$ in 30 seconds. Fig. 6 shows the generation of the tsunami source during the implementation of Scenario 2 and the propagation of wave fronts from this source. 

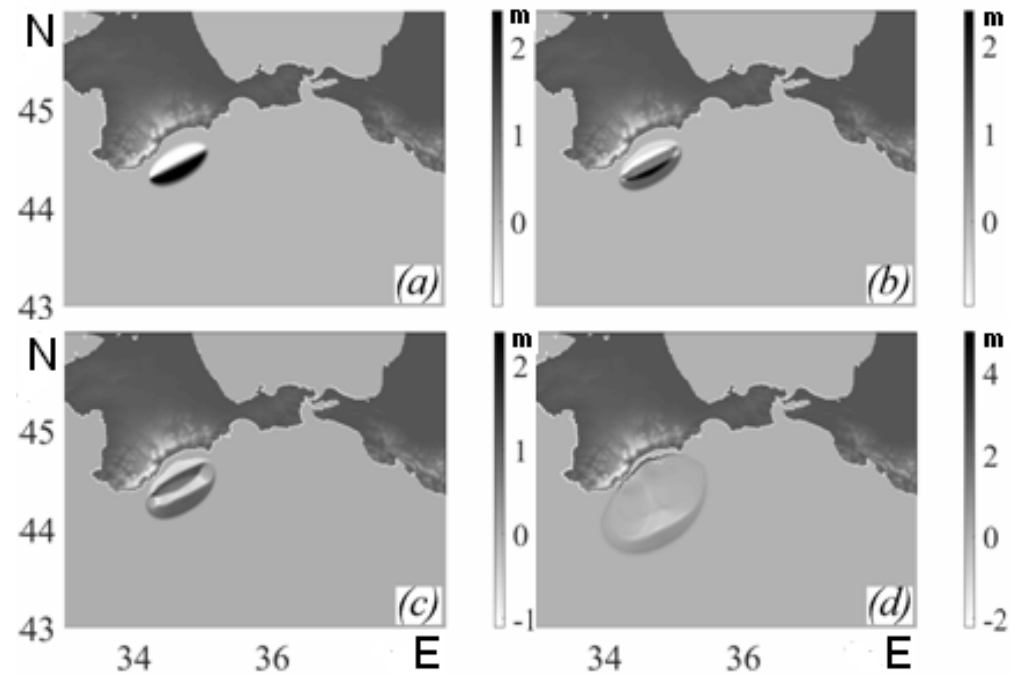

F i g. 6. Generation of tsunami source and position of the tsunami wave fronts in the Black Sea water area, Scenario $2(\mathrm{M}=7.5$ ) for 4 time moments: $a) t=30 \mathrm{~s} ; b) t=1 \mathrm{~min} ; c) t=2 \mathrm{~min}$; $d$ ) $t=7 \mathrm{~min}$

Note that (Fig. 6, $b, 6, c$ ), in contrast to the previous scenario, a tsunami begins with a rundown of the wave from the shore (depression wave) with a vertical component of up to $0.5 \mathrm{~m}$ (Fig. 6, $d$ ). The next wave goes to the shore with a height of up to $2-3 \mathrm{~m}$. In Fig. 7 it is clearly seen that for this scenario, the highest wave heights were observed in the range $34.2^{\circ}-34.9^{\circ} \mathrm{E}$, between Yalta and Sudak, and the maximum rise was $7 \mathrm{~m}$. However, further distribution along the coast, as in Scenario $1(\mathrm{M}=7)$, occurred evenly, with an average height of $1 \mathrm{~m}$.

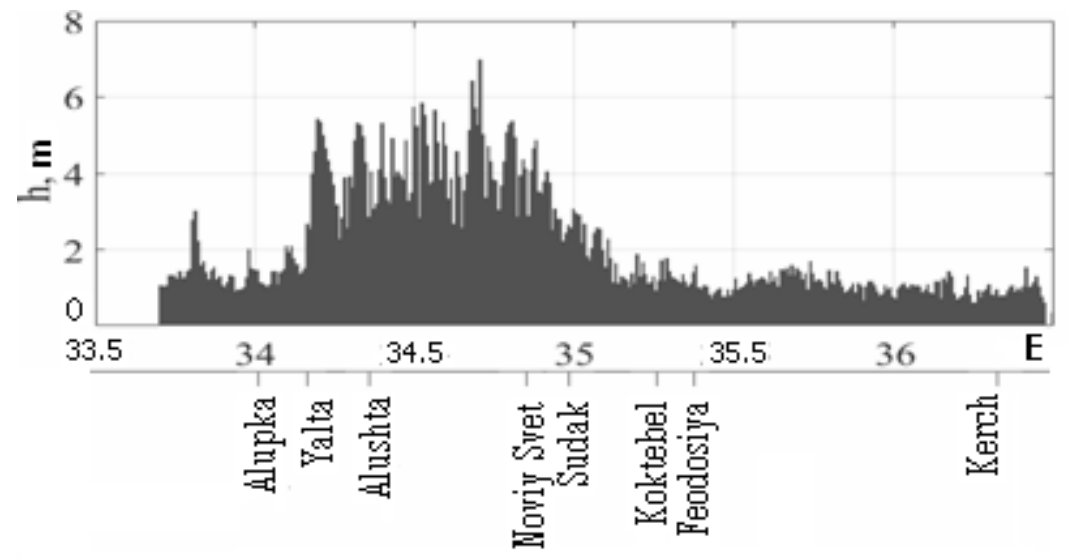

F i g. 7. 2D histogram of distribution of the wave maximum heights on the 3-meter isobath near the Crimean coast, Scenario $2(\mathrm{M}=7.5)$

Fig. 8 shows the results of numerical simulation of tsunami wave propagation in the Kerch Strait. Here, the wave height compared with the heights in the Black Sea was significantly lower - no more than $30 \mathrm{~cm}$. The leading front of the arcuate 116

PHYSICAL OCEANOGRAPHY VOL. 27 ISS. 2 (2020) 
shape after $1 \mathrm{~h} 40$ min (Fig. 8, b) reaches the Crimean Bridge with a wave height of $\sim 20 \mathrm{~cm}$. At the following time the height of water rise near the Crimean Bridge does not exceed $20-25 \mathrm{~cm}$.
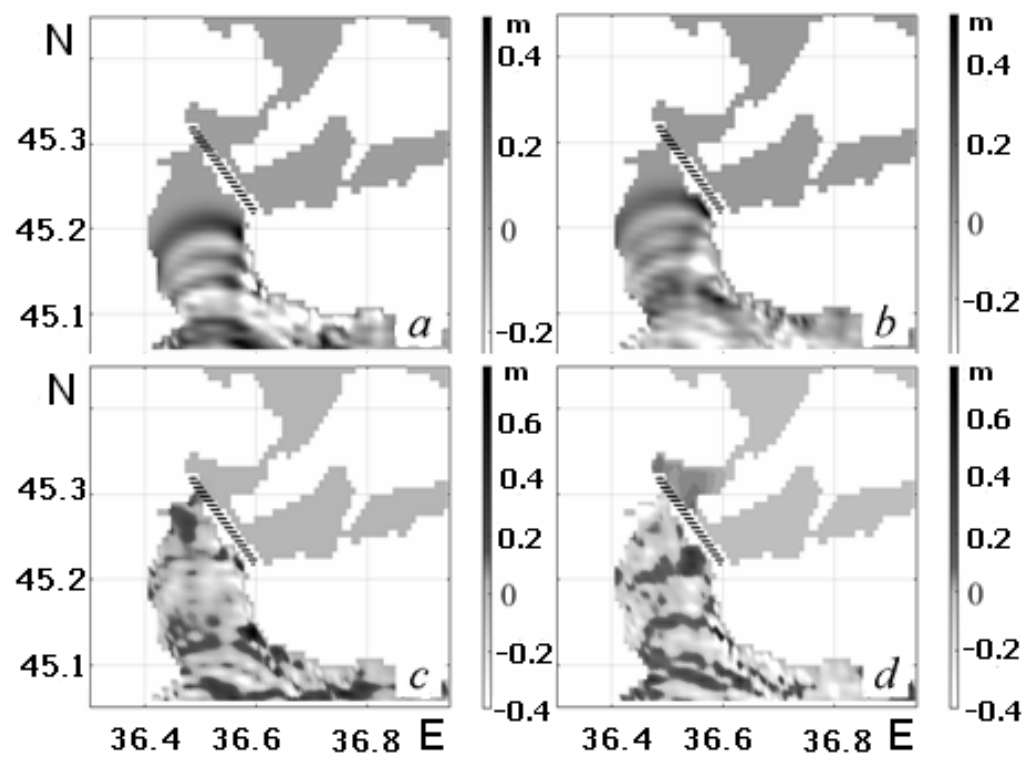

F i g. 8. Position of the tsunami wave fronts in the Kerch Strait water area, Scenario 2: $a$ ) $t=1 \mathrm{~h} 35 \mathrm{~min}$; b) $t=1 \mathrm{~h} 40 \mathrm{~min}$; ) $t=2 \mathrm{hrs}$; $) t=2 \mathrm{hrs} 20 \mathrm{~min}$. Dark line denotes schematic location of the bridge

\section{Numerical simulation of a tsunami with a hypothetical earthquake source $(M=8)$, localized in the fault zone of the Earth's crust near the Crimean Peninsula (Scenario 3)}

To implement Scenario 3, a seismic source of the earthquake was selected (shown by the blue line in Fig. 1) with a magnitude of $\mathrm{M}=8$ and localization on line 2 of the Earth's crust break up (Fig. 1). The movement of the blocks began at the same time: within $30 \mathrm{~s}$, the block oriented toward the coast fell $1.5 \mathrm{~m}$, and the block oriented towards the sea within $30 \mathrm{~s}$ rose $4.5 \mathrm{~m}$.

Fig. 9 shows the stages of the evolution of tsunami waves in the Black Sea for this scenario: Fig. 9, $a$ and 9, $b$ show the beginning of wave propagation after the end of movement of the blocks of the seismic source; Fig. 9, $c, 9, d$ show that the wave that moves northward from the source to the coast is a "depression wave," that is, the tsunami in this section of the water area will begin with the wave rundown from the coast; according to Fig. 9, $f$, the wave reaches the Crimean coast in about 10 minutes, while the leading front is approximately $-2 \mathrm{~m}$. 

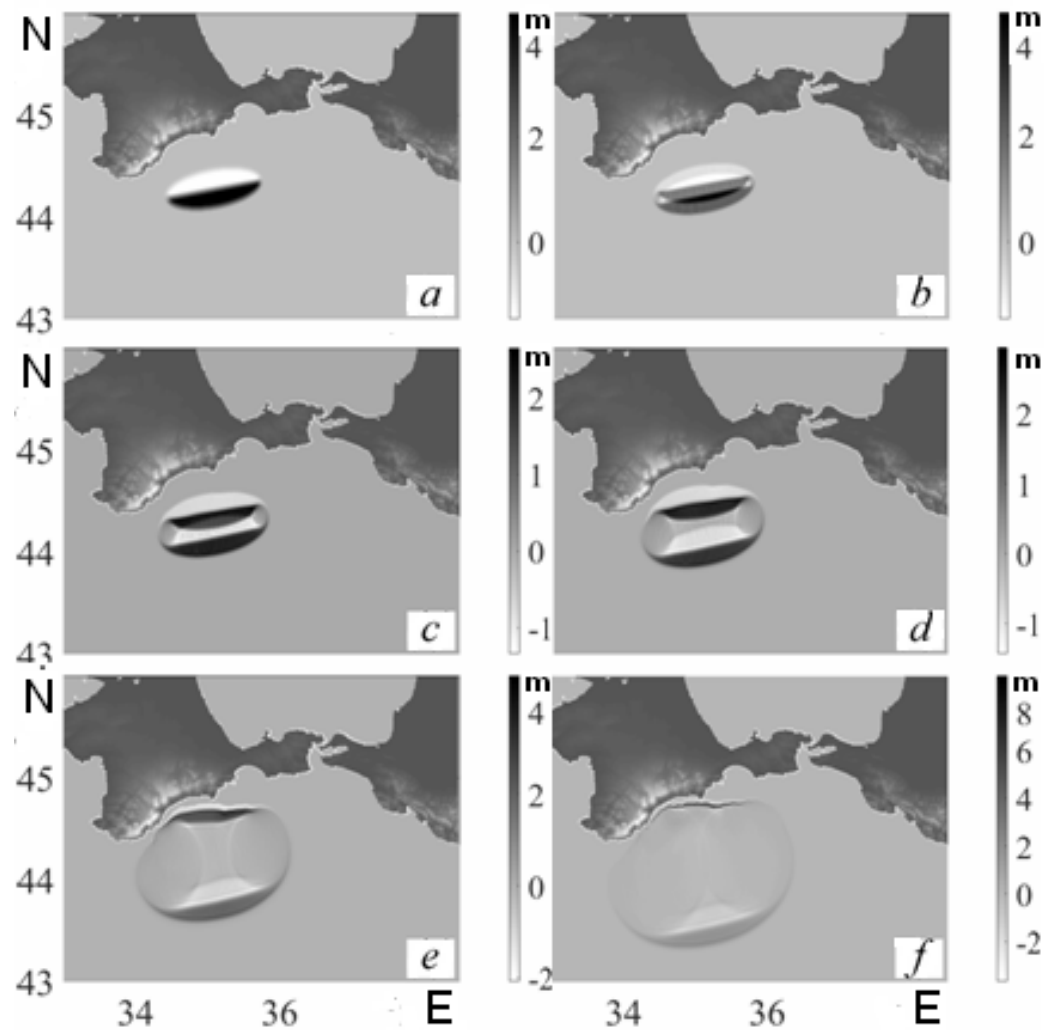

F i g. 9. Generation of tsunami source and position of the tsunami wave fronts in the Black Sea water area, Scenario $3(\mathrm{M}=8)$ for 6 time moments: $a) t=30 \mathrm{~s} ; b) t=1 \mathrm{~min} ; c) t=2 \min ; d) t=3 \min ; e) t=$ $=7 \mathrm{~min} ;$ f) $t=10 \mathrm{~min}$

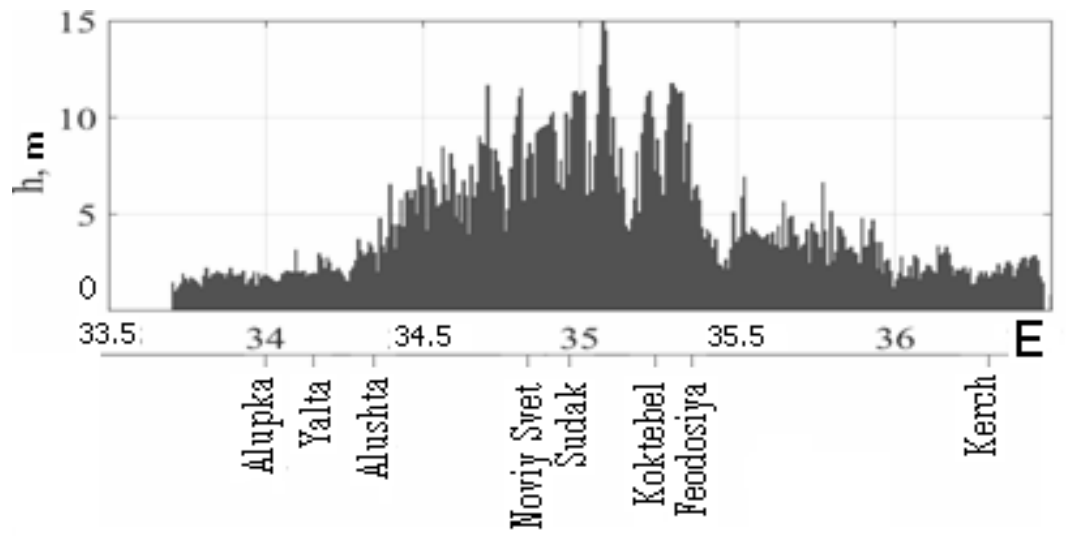

F i g. 10. 2D histogram of distribution of the wave maximum heights on the 3-meter isobath near the Crimean coast, Scenario $3(\mathrm{M}=8)$ 
In Fig. 10 it is clearly seen that the maximum wave heights are observed in the range $34.7^{\circ}-35.45^{\circ} \mathrm{E}$ (between Alushta and Feodosiya), the height of the sea level rise here reached 6-8 m, which exceeds the similar values in the two previous scenarios by $1-3 \mathrm{~m}$. On the rest of the isobath, the wave height did not exceed $2-3 \mathrm{~m}$. The maximum height tsunami waves, up to $15 \mathrm{~m}$, are in the Sudak area.

Fig. 11 shows the evolution of tsunami waves in the Kerch Strait water area according to Scenario 3. It is clearly seen that the wave of an arc-like shape with a height of about $0.5 \mathrm{~m}$ first reaches the eastern pillars of the bridge in the area of the Tuzla Spit. It approaches the Crimean Bridge in $1 \mathrm{~h} 25 \mathrm{~min}$ after the generation begins (Fig. 11, c). After 10 minutes, the leading front reaches the western pillars of the bridge, while it has a height of $30 \mathrm{~cm}$. Further, the wave practically does not pass northward beyond the Chushka Spit, the main oscillations are noticeable in the southern half of the Kerch Strait.
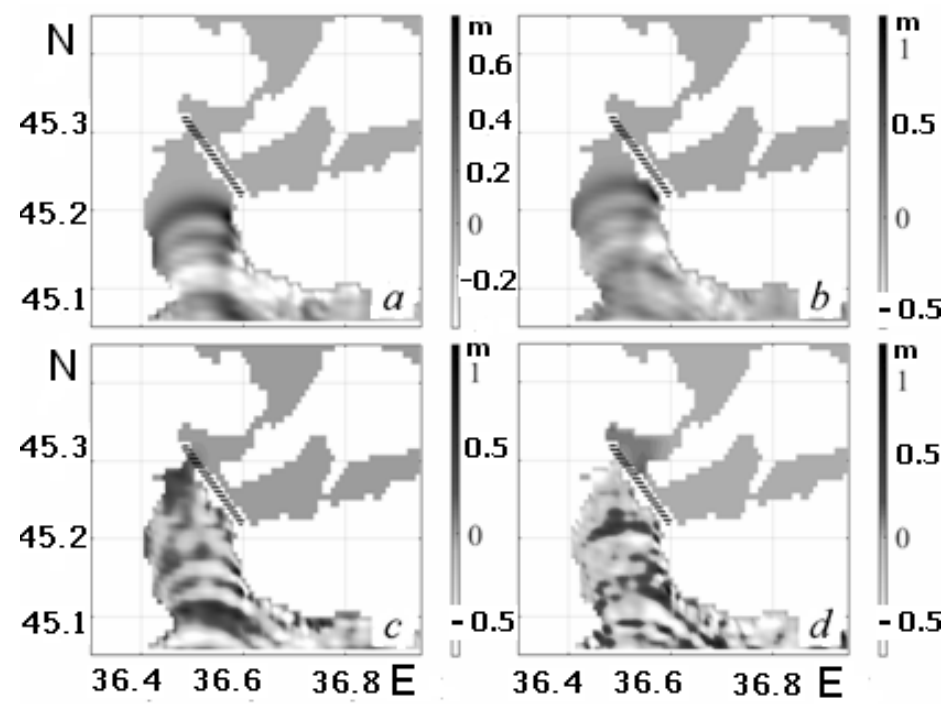

F i g. 11. Position of the tsunami wave fronts in the Kerch Strait water area, Scenario 3: a) $t=1 \mathrm{~h} 25 \mathrm{~min}$; b) $t=1 \mathrm{~h} 30 \mathrm{~min}$; ) $t=1 \mathrm{~h} 35 \mathrm{~min}$; $) t=1 \mathrm{~h} 40 \mathrm{~min}$. Dark line denotes schematic location of the bridge

\section{Analysis of the results of numerical simulation of tsunamis during strong and catastrophic earthquakes in the Black Sea with sources localized near the Crimean Peninsula}

Fig. 12 shows the histograms of the distribution of the maximum tsunami wave heights for the eastern and western coasts of the Kerch Strait. The geographic location of the Crimean Bridge pillars in the projection (cross-section in longitude) is marked in red. It should be noted that in the considered scenarios of the occurrence and propagation of tsunami waves with increasing magnitude of the seismic source, the level of water rise on three-meter isobaths in the Kerch Strait also increases. It can be seen that during the Scenario 1 implementation, 
the maximum height of the water level rise at the western and eastern pillars of the bridge was 0.32 and $0.65 \mathrm{~m}$, respectively (the upper part of Fig. 12).

In general, the height was a little less than $1 \mathrm{~m}$ in the strait water area. According to Scenario 2, the maximum height of sea level rise in the region of the western pillars of the bridge was $35 \mathrm{~cm}$ (middle part of Fig. 12), in the region of the eastern pillars near $0.7 \mathrm{~m}$. It also should be noted that at the Kerch Strait entrance from the Black Sea, the wave heights on the $3 \mathrm{~m}$ isobath reached $1.5 \mathrm{~m}$. When implementing Scenario 3 with a hypothetical block source and $\mathrm{M}=8$, the maximum tsunami wave heights in the region of the western pillars of the bridge were $0.5 \mathrm{~m}$, in the region of the eastern pillars $-1.95 \mathrm{~m}$; the maximum height for this scenario is $3.2 \mathrm{~m}$ (lower part of Fig. 12).

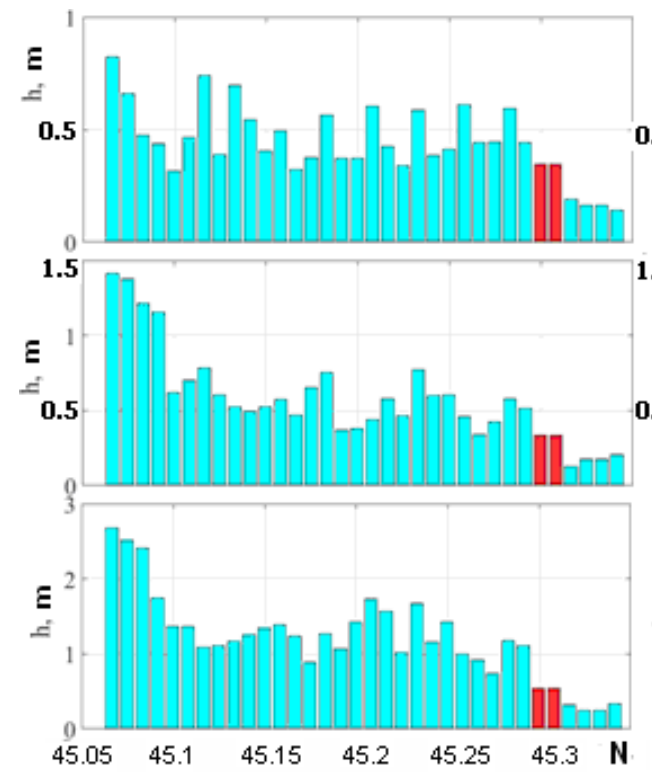

The western coast of the strait

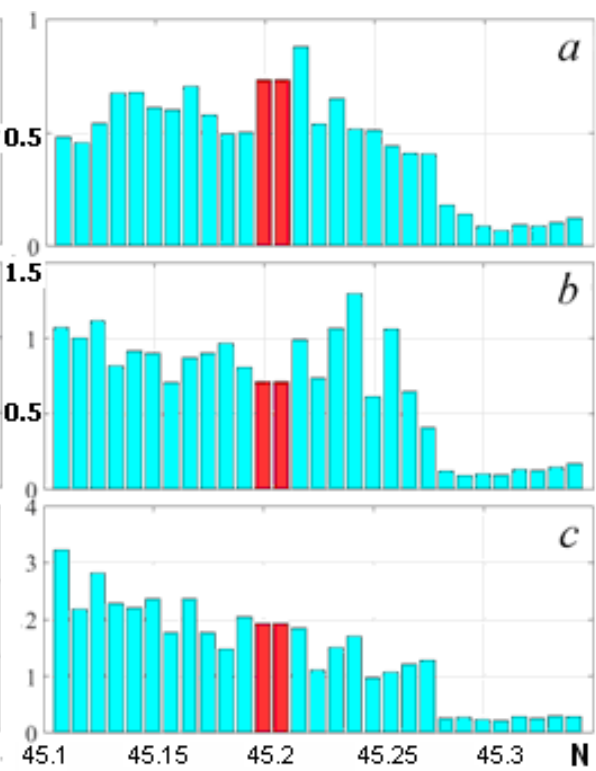

The eastern coast of the strait

F i g. 12. Histograms of distribution the tsunami wave maximum heights on the 3-meter isobath along the Kerch Strait coast near the Crimean Bridge, Scenario $1(M=7)$ - above, Scenario $2(M=$ $=7.5)$ - in the middle, Scenario $3(\mathrm{M}=8)-$ below. Red color indicates locations of the Crimean Bridge western and eastern pillars

Fig. 13 shows a generalized histogram for all three scenarios. It can be seen that in the region of the western pillars of the bridge the tsunami wave heights for all scenarios do not exceed $0.3-0.5 \mathrm{~m}$ (the brown color indicates the maximum height of sea level rise in western and eastern bridge pillars for Scenario 1, the gray - for Scenario 2, the orange - for Scenario 3), and in the region of eastern pillars, the range of possible wave heights lies in the range $0.6-1.95 \mathrm{~m}$. This data is given in Table 2.

Comparison of the three scenarios showed that the maximum wave heights in the Kerch Strait water area were observed during the implementation of Scenario 3 
$(\mathrm{M}=8)$ : they were on average 1-1.2 $\mathrm{m}$ higher than the corresponding values in the other two scenarios.

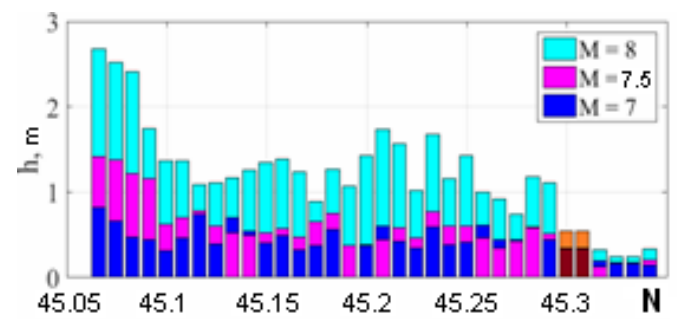

The western coast of the strait

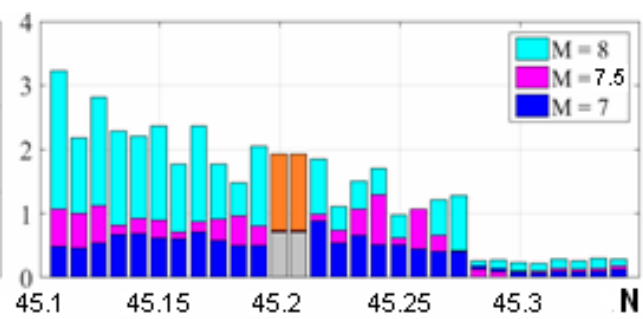

The eastern coast of the strait

F i g. 13. Comparative histograms of distribution of the tsunami wave maximum heights along the Kerch Strait coast for 3 scenarios. Brown color shows locations of the Crimean Bridge western and eastern pillars, Scenario $1(\mathrm{M}=7)$, grey color - Scenario $2(\mathrm{M}=7.5)$, orange color - Scenario $3(\mathrm{M}=8)$

Table 2

Wave height maximum values at the Crimean Bridge pillars

\begin{tabular}{c|c|c}
\hline \multirow{2}{*}{ Scenario number } & \multicolumn{2}{|c}{ Maximum rise } \\
\cline { 2 - 3 } & western pillars & eastern pillars \\
\hline 1 & $0.32 \mathrm{~m}$ & $0.65 \mathrm{~m}$ \\
2 & $0.35 \mathrm{~m}$ & $0.70 \mathrm{~m}$ \\
3 & $0.50 \mathrm{~m}$ & $1.95 \mathrm{~m}$ \\
\hline
\end{tabular}

\section{Discussion}

The present paper aim is to obtain wave characteristics in the Kerch Strait water area from earthquake sources located in the southeast of the Crimean Peninsula, for which three scenarios were considered. Comparing the work [13] that was carried out earlier for hypothetical sources of earthquakes localized before entering the Kerch Strait, and the present work, considering seismic sources located in the south-west of the Crimean Peninsula, it was shown that in earthquakes with the same magnitudes wave heights in the strait, in particular in the Crimean Bridge area, have significantly different values. Thus, for example, the maximum wave height at the eastern pillars of the Crimean Bridge, according to [13], was $1.5 \mathrm{~m}$, and, according to the computations presented in this work, the tsunami wave height from the source located in the south-west of the Crimean Peninsula, at the eastern pillars of the bridge is $0.5 \mathrm{~m}$. However, in the event of a catastrophic earthquake with a magnitude of $\mathrm{M}=8$ and with a seismic source located in the zone of active faults of the Crimean Peninsula Earth's crust, in the Kerch Strait, the possible maximum wave height in the region of the western pillars of the bridge is about $0.5 \mathrm{~m}$, in the region of eastern pillars up to $1.9 \mathrm{~m}$. 
Numerical modeling of the historical earthquake of September 12, 1927 off the coast of Crimea was also carried out in $[8,9,11]$. Computations in these works were carried out for similar forms of the earthquake source with a magnitude of $\mathrm{M}=7$. Since the Crimean Peninsula coast and the northeastern part of the Black Sea were considered in detail in $[8,11]$, the purpose of the present research was to estimate wave characteristics in Kerch Strait water area. Here, the virtual tide gauges were put, for comparison, in [8] and [11] only a few points on the Crimean coast and only one point at the Kerch Strait (Kerch) entrance could be found. A comparison of the tsunami simulation results obtained in the indicated works and the numerical simulation carried out in this work during the implementation of Scenario 1 and magnitude $M=7$ with a seismic source of elliptical type, localized in accordance with historical earthquake data, is given in Table 3.

T a ble 3

Comparison of the values of the sea level maximum rise near the settlements on the Crimean and the Kerch Strait coasts (Scenario 1 and articles [8, 11])

\begin{tabular}{lcc|c}
\hline \multicolumn{1}{c|}{ Coastal settlement } & Scenario 1 & Paper [8] & Paper [11] \\
\hline Alupka & $0.90 \mathrm{~m}$ & $0.4 \mathrm{~m}$ & $0.7 \mathrm{~m}$ \\
Yalta & $1.30 \mathrm{~m}$ & $1.5 \mathrm{~m}$ & $1.0 \mathrm{~m}$ \\
Sudak & $1.00 \mathrm{~m}$ & $0.4 \mathrm{~m}$ & $0.6 \mathrm{~m}$ \\
Feodosiya & $0.40 \mathrm{~m}$ & $0.5 \mathrm{~m}$ & $0.4 \mathrm{~m}$ \\
Kerch & $0.32 \mathrm{~m}$ & - & $0.4 \mathrm{~m}$ \\
\hline
\end{tabular}

You can see that for all the items given in Table 3, the computation data are quite close, although for Kerch it was possible to cite only the data from [11].

\section{Conclusion}

As follows from the computation presented in this paper, under a strong earthquake with a magnitude of $\mathrm{M}=7$, simulating the events of September 12, 1927 near the Crimean coast, the height of sea level rise in the region of Yalta and Alushta can reach 2.5-2.7 m. The same localization of the source, but the greater magnitude of the earthquake $(\mathrm{M}=7.5)$ and a different shape of the source (block source, consisting of two semi-ellipses), the height of the water rise between Sudak and Koktebel can reach $7 \mathrm{~m}$. A catastrophic earthquake with magnitude $\mathrm{M}=8$ (Scenario 3) was considered as a hypothetical event with the source (close localization to the historical 12 September 1927 earthquake) located in the zone of the active Earth's crust faults in the considered water area. For this scenario, the obtained estimates of the maximum wave heights reached $15 \mathrm{~m}$, with the highest values obtained for the Black Sea between Alushta and Feodosiya.

The results of numerical simulation also demonstrate that in the region of the western pillars of the Crimean Bridge, the tsunami wave heights for all 
scenarios do not exceed $0.3-0.5 \mathrm{~m}$, while in the region of the eastern pillars the range of possible wave heights lies in the range $0.6-1.95 \mathrm{~m}$.

The presented scenarios of hypothetical tsunamigenic earthquakes in the northeastern part of the Black Sea demonstrate that in the event of a repeat of September 12, 1927 with a greater magnitude of the earthquake, the infrastructure of the Kerch Strait, including the bridge itself, can be attacked by tsunamis of sufficiently high height.

\section{REFERENCES}

1. Nikonov, A.A., 2002. Crimean Earthquakes of 1927: Unknown Phenomena of Sea. Priroda, 9, pp. 13-20. Available at: https://priroda.ras.ru/pdf/2002-09.pdf [Accessed: 05.05.2020] (in Russian).

2. Nedelkin, E.V., 2019. To the Question of the Consequences of the Crimean Earthquake of September 11, 1927 on the Territory of the Sevastopol District of the Autonomous Crimean Socialist Soviet Republic. The Black Sea Region. History, Politics, Culture. Series B: Modern and Contemporary History, 28, pp. 57-66. doi:10.5281/zenodo.3476029 (in Russian).

3. Bagrova, L.A., Smirnov, V.O., Gunkina, I.Yu. and Zmerzlaya, K.S., 2013. Natural Hazards in the Crimea. Geopolitics and Ecodynamics of Regions, 9(2), pp.115-126. Available at: http://geopolitika.cfuv.ru/wp-content/uploads/2016/11/013bagr2.pdf [Accessed: 05 May 2020] (in Russian).

4. Kim, A.Yu. and Rassada, A.A., 2018. Construction of Earthquake Resistant Houses in the Crimea after the Crimean Earthquake. In: G.Yu. Gulyaev, 2018. Student Research. Penza: Nauka i Prosveshchenie. Part 1, pp. 52-55 (in Russian).

5. Nikonov, A.A., Gusiakov, V.K. and Fleifel', L.D., 2018. Assessment of the Tsunami Hazard on the Russian Coast based on a New Catalogue of Tsunamis in the Black Sea and the Sea of Azov. Russian Geology and Geophysics, 59(2), pp. 193-205. https://doi.org/10.1016/j.rgg.2018.01.016

6. Papadopoulos, G.A., Diakogianni, G., Fokaefs, A. and Ranguelov, B., 2011. Tsunami Hazard in the Black Sea and the Azov Sea: A New Tsunami Catalogue. Natural Hazards and Earth System Sciences, 11(3), pp. 945-963. doi:10.5194/nhess11-945-2011

7. Grigorash, Z.K., 1959. Tsunami Propagation of 1927 in the Black Sea. In: MHI, 1959. Trudy Morskogo Gidrofizicheskogo Instituta [Proceedings of Marine Hydrophysical Institute of AS USSR]. Moscow: MHI. Iss. 18, pp. 113-116 (in Russian).

8. Dotsenko, S.F. and Ingerov, A.V., 2010. Numerical Modeling of the Propagation and Strengthening of Tsunami Waves near the Crimean Peninsula and the Northeast Coast of the Black Sea. Physical Oceanography, 20(1), pp. 1-13. https://doi.org/10.1007/s11110-010-9063-5

9. Dotsenko, S.F. and Ingerov, A.V., 2010. Numerical Analysis of the Propagation and Amplification of Tsunami Waves on the Northwest shelf of the Black Sea. Physical Oceanography, 20(5), pp. 325-334. https://doi.org/10.1007/s11110-011-9088-4

10. Dotsenko, S.F., 2012. Numerical Simulation of Tsunami in the Black, the Sea of Azov and the Caspian Sea as an Essential Element of Tsunami Early Warning Regional Systems. In: MHI, 2012. Ecological Safety of Coastal and Shelf Zones and Comprehensive Use of Shelf Resources. Sevastopol: MHI, 2012. Iss. 26, vol. 2. pp. 287-300 (in Russian). 
11. Bazykina, A.Yu., Mikhailichenko, S.Yu. and Fomin, V.V., 2018. Numerical Simulation of Tsunami in the Black Sea Caused by the Earthquake on September 12, 1927. Physical Oceanography, 25(4), pp. 295-304. doi:10.22449/1573-160X-20184-295-304

12. Zaitsev, A.I. and Pelinovsky, E.N., 2011. Forecasting of Tsunami Wave Heights at the Russian Coast of the Black Sea. Oceanology, 51(6), pp. 907-915. https://doi.org/10.1134/S0001437011050225

13. Lobkovsky, L.I., Mazova, R.Kh., Baranova, E.A. and Tugaryov, A.M., 2018. Numerical Simulation of Propagation of the Black Sea and the Azov Sea Tsunami through the Kerch Strait. Physical Oceanography, 25(2), pp. 102-113. doi:10.22449/1573-160X-2018-2-102-113

14. Isvoranu, D. and Badescu, V., 2012. Hydrodynamics of Tsunamis Generated by Asteroid Impact in the Black Sea. Open Physics, 10(2), pp. 429-446. doi:10.2478/s11534-012-0012-4

15. Mazova, R.Kh. and Tresvyatskaya, E.A., 2006. Numerical Modeling of the Generation of Long Waves by a Dynamic Seismic Source and Their Propagation in the Black Sea. Russian Journal of Earth Sciences, 8(6), ES6003. doi:10.2205/2006ES000212

16. Moldovan, I.A., Diaconescu, M., Partheniu, R., Constantin, A.P., Popescu, E. and Toma-Danila, D., 2017. Probabilistic Seismic Hazard Assessment in the Black Sea Area. Romanian Journal of Physics, 62(5-6), 809. Available at: https://www.nipne.ro/rjp/2017_62_5-6/RomJPhys.62.809.pdf [Accessed: 13 May 2020].

17. Yalçiner, A., Pelinovsky, E., Talipova, T., Kurkin, A., Kozelkov, A. and Zaitsev, A., 2004. Tsunamis in the Black Sea: Comparison of the Historical, Instrumental, and Numerical Data. Journal of Geophysical Research: Oceans, 109(C12), C12023. doi:10.1029/2003JC002113

18. Schiermeier, Q., 2005. Tsunamis: A Long-Term Threat. Nature, 433(7021), pp. 4. https://doi.org/10.1038/433004a

19. Vinokurov, N.I., Korzhenkov, A.M. and Rodkin, M.V., 2015. Seismic Hazard Assessment of the Kerch Strait Region by Archeoseismology Data. Problems of Engineering Seismology, 42(2), pp. 51-66 (in Russian).

20. Nikonov, A.A., 1994. The Signs of Neotectonic Activity in the Zones of the South Azov and Kerch Faults. Geotektonika, (5), pp. 16-28 (in Russian).

21. Gorshkov, A.I., Soloviev, A.A. and Zharkikh, Y.I., 2017. Morphostructural Zoning of the Mountainous Crimea and the Possible Locations of Future Earthquakes. Journal of Volcanology and Seismology, 11(6), pp. 407-412. https://doi.org/10.1134/S0742046317060021

22. Wells, D.L. and Coppersmith, K.J., 1994. New Empirical Relationships Among Magnitude, Rupture Length, Rupture Width, Rupture Area and Surface Displacement. Bulletin of the Seismological Society of America, 84(4), pp. 9741002.

23. Sielecki, A. and Wurtele, M.G., 1970. The numerical Integration of the Nonlinear Shallow-Water Equations with Sloping Boundaries. Journal of Computational Physics, 6(2), pp. 219-236. doi:10.1016/0021-9991(70)90022-7

About the authors:

Elena A. Baranova, Master of the Applied Mathematics Department, Institute of Radioelectronics and Information Technologies (IRIT), Nizhny Novgorod State Technical University 
n.a. R.E. Alekseev (NNSTU) (24 Minin St., Nizhny Novgorod, 603950, Russian Federation), elenabaranova5995@gmail.com

Raisa Kh. Mazova, Professor of the Applied Mathematics Department, Institute of Radioelectronics and Information Technologies (IRIT), Nizhny Novgorod State Technical University n.a. R.E. Alekseev (NNSTU) (24 Minin St., Nizhny Novgorod, 603950, Russian Federation), Dr. Sci. (Phys.-Math.), Professor, Moscow Institute of Physics and Technology (National Research University), (9 Institutskiy Lane, Dolgoprudny, Moscow region, 141701, Russian Federation), Scopus Author ID: 6506297372, raissamazova@yandex.ru

Contibution of the authors:

Raisa Kh. Mazova - general scientific supervision of research; formulation of the goals and objectives of the study; discussion of the research results; analysis and synthesis of research results; formulation of conclusions; writing annotations; critical analysis and revision of the text; editing and addition of the article text

Elena A. Baranova - selection and justification of numerical methods for solving equations; qualitative and quantitative analysis of the results; processing and description of the research results; analysis of materials on the research topic; reference review on research; reference review of foreign sources; computer implementation of algorithms; development and debugging of a computer program for solving a problem; computer works

All the authors have read and approved the final manuscript.

The authors declare that they have no conflict of interest. 